\title{
ARTIGO
}

\section{PROGRAMA COMPUTACIONAL PARA O DIMENSIONAMENTO DE PILARES MISTOS DE AÇO E CONCRETO SUBMETIDOS À COMPRESSÃO CENTRADA ${ }^{1}$}

\author{
Heriston Rodrigues ${ }^{2}$ \\ Geraldo Donizetti de Paula \\ Jaime Florêncio Martins
}

\begin{abstract}
RESUMO
O avanço das construções metálicas no Brasil demanda profissionais capacitados e dotados de ferramentas eficazes na elaboração de projetos. Desenvolveu-se um programa capaz de dimensionar pilares mistos de aço e concreto submetidos à compressão centrada, atendendo as exigências normativas brasileiras. A ferramenta foi construída no ambiente de programação Notepad++ v7.5.6 seguindo os procedimentos propostos pela norma brasileira NBR 8800 (ABNT, 2008). Realizou-se também um processo de validação de seus resultados comparando-os a exemplos de aplicação desenvolvidos analiticamente com auxílio de planilhas eletrônicas. O programa fornece resultados precisos, pode auxiliar profissionais no desenvolvimento de projetos, é capaz de ser uma ferramenta complementar no processo de ensino e na disseminação do sistema estrutural metálico misto.
\end{abstract}

Palavras-chave: Estrutura mista. Pilar misto. Programa de dimensionamento.

\section{INTRODUÇÃO}

De acordo com Alva e Malite (2005), nas construções mistas utilizava-se, no início do século, o concreto como material de revestimento, tendo como finalidade a proteção dos perfis de aço contra o fogo e a corrosão. A resistência do concreto era ignorada no dimensionamento, embora tivesse uma participação em termos estruturais.

A evolução da técnica permitiu, segundo Campos (2006), que tanto em edifícios baixos como em edifícios altos se encontrem aplicações práticas para o uso dos pilares mistos de aço e concreto. Além disso, se consegue uma maior racionalização de espaços com o conhecimento dos métodos construtivos e de dimensionamento dos pilares mistos (MENDONÇA; VIEIRA; VENÂNCIO, 2005).

\footnotetext{
${ }^{1}$ Como citar este artigo: RODRIGUES, Heriston; PAULA, Geraldo Donizete de; FLORÊNCIO, Jaime. Programa computacional para o dimensionamento de pilares mitos de aço e concretos submetidos à compressão centrada. ForScience: revista científica do IFMG, Formiga, v. 7, n. 2, e00690, jul./dez. 2019. DOI: 10.29069/forscience. 2019v7n2.e690

${ }^{2}$ Autor para correspondência: Heriston Rodrigues, e-mail: heriston.rodrigues@ifmg.edu.br.
} 
Esse avanço da construção metálica no Brasil ganha, a cada dia, um ritmo mais acelerado, exigindo dos profissionais uma melhor qualificação que subsidie a criação de soluções estruturais inovadoras que atendam às demandas do mercado da construção civil.

Nesse cenário, as estruturas mistas se destacam por possibilitarem soluções estruturais ágeis, econômicas e ecologicamente corretas para aplicação em edifícios de múltiplos pavimentos, sejam estes residenciais, comerciais ou industriais, de pequeno ou grande porte. Abre ainda à possibilidade de se edificar primeiramente a estrutura de aço, com função de resistir apenas às ações da etapa construtiva e, posteriormente, completar a capacidade resistente da estrutura com o concreto para resistir às ações de uso normal (CHAVES, 2013).

Em um meio em que os processos são mais rápidos, provocando, por parte do engenheiro projetista da área de estruturas, respostas eficientes com intuito de atender o mercado, os aplicativos são ferramentas que auxiliam o processo de criação e análise estrutural em diversos projetos, constituindo-se peças fundamentais na etapa de projeto. Tais aplicativos conferem agilidade e confiabilidade ao processo.

Os softwares de dimensionamento de pilares mistos aço-concreto ainda são raros no mercado brasileiro, principalmente quanto às verificações recomendadas pela norma NBR 8800 (ABNT, 2008). Um sistema para dimensionamento de pilares mistos, segundo a norma brasileira, pode auxiliar profissionais na execução de projetos em estruturas mistas, além de facilitar a execução de diversas alternativas estruturais, tornando tal processo eficiente, econômico e eficaz.

Além disso, as normativas que regem a metodologia de dimensionamento dos elementos mistos nem sempre são de simples e breve interpretação. Interessa, portanto, sistematizar métodos de cálculo e automatizá-los para que possam ser empregados (RODRIGUES, 2008).

Uma ferramenta computacional pode também ser utilizada como assistente no processo de ensino do sistema estruturado em aço, facilitando o dimensionamento e a análise de diversas verificações realizadas em sala de aula, promovendo, desta maneira, a interatividade do conteúdo. Possibilita ainda aos discentes um amplo foco no conceito e aplicação da base teórica em atividades prática, de forma ágil e didática.

A construção estruturada em aço, em expansão, necessita de pesquisas que auxiliem no entendimento do processo, nas técnicas de projetos e até no esclarecimento quanto a procedimentos exigidos nas normas técnicas, tornando a solução mais atrativa ao mercado.

Esta pesquisa tem como objetivo geral desenvolver um programa capaz de dimensionar pilares mistos de aço e concreto submetidos à compressão centrada, baseado nas 
recomendações e equacionamentos descritos pela norma NBR 8800 (ABNT, 2008), com seções totalmente ou parcialmente revestidas com concreto composta por perfis I ou $\mathrm{H}$.

\section{REFERENCIAL TEÓRICO}

Uma estrutura mista é formada por um grupo de sistemas mistos e é empregada usualmente na construção de edificações e pontes (QUEIROZ; PIMENTA; MARTINS, 2012).

De acordo com Cardoso (2013), as estruturas mistas são mais utilizadas na construção de edifícios comerciais, edifícios industriais, edifícios de escritórios, parques de estacionamento, pontes, edifícios de habitação e hospitais.

Os pilares mistos são elementos estruturais compostos por um perfil de aço e por concreto armado, trabalhando conjuntamente (FAKURY; CASTRO E SILVA; CALDAS, 2016).

Ainda de acordo com Fakury, Castro e Silva e Caldas (2016), a combinação entre o perfil de aço e o concreto armado proporciona diversas consequências favoráveis. Entre elas podem-se citar, como exemplo, uma melhor proteção ao fogo e à corrosão atmosférica, em relação aos pilares de aço, e a possibilidade de alcance de capacidade resistente necessária com dimensões menores na seção transversal, além de um aumento ductilidade, em relação aos pilares de concreto armado. Para Figueiredo (1998), outra vantagem propiciada, ao se trabalhar o conjunto aço e concreto, é o impedimento da maioria dos casos de flambagens global e local.

Os pilares mistos podem ser classificados em dois grupos principais:

i. Com seções transversais total ou parcialmente revestidas com concreto compostas com perfil de aço I ou H soldado ou laminado (FIG. 1a e FIG. 1b)

ii. Com seções transversais preenchidas com concreto compostas com perfil de aço tubular retangular ou circular. 


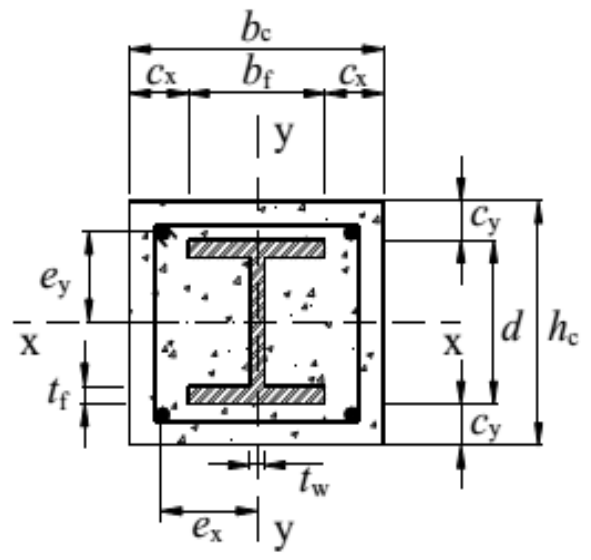

(a)

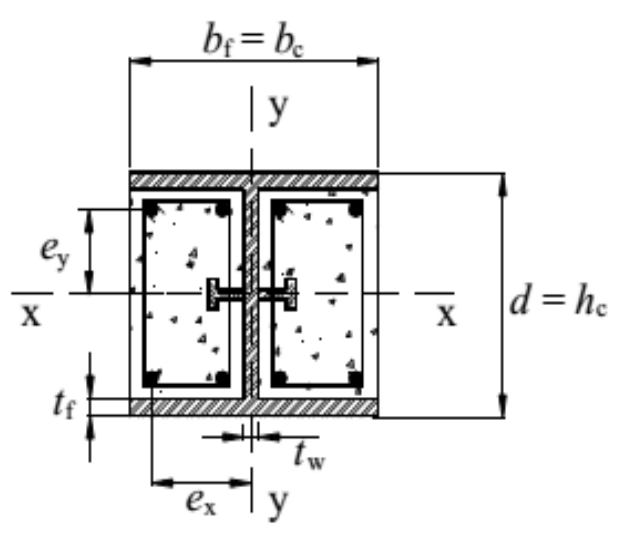

(b)

Figura 1 - Seções transversais de pilares misto aço-concreto parcialmente e totalmente revestidos Fonte: NBR 8800 (ABNT, 2008).

De acordo com Silva (2012), o dimensionamento de pilares mistos no Brasil é realizado por dois modelos simplificados que utilizam das mesmas curvas de dimensionamento aplicadas a pilares de aço e é aplicável somente a seções com dupla simetria.

Segundo Fabrizzi (2007), as normas e procedimentos de cálculos de pilares mistos podem ser divididos em duas linhas de raciocínio:

i. Pilares de concreto com armaduras especiais constituídas pelo perfil de aço;

ii. Pilares de aço com resistência e rigidez modificadas pela presença do concreto.

Como o dimensionamento dos pilares mistos são realizados por método simplificado, devem ser respeitadas as três hipóteses básicas de dimensionamento indicadas pela norma NBR 8800 (ABNT, 2008) e comentadas por Fakury, Castro e Silva e Caldas (2016):

i. Há interação completa entre o concreto e o aço. A interação é assegurada pelo contato das superfícies dos materiais, devendo os perfis se encontrarem isentos de qualquer tipo de pintura;

ii. As imperfeições iniciais são consistentes com aquelas adotadas para a determinação da resistência de barras de aço submetidas à compressão axial. Adotando-se para os pilares mistos, a mesma curva para o fator de redução associado à resistência à compressão dos pilares de aço, $\chi$, bastando obter o índice de esbeltez reduzido do pilar misto; 
iii. A flambagem local para força axial e momento fletor não pode ser um estadolimite último predominante, ou seja, o pilar misto não deve estar submetido à flambagem local nos elementos de aço.

\section{MATERIAIS E METÓDOS}

O desenvolvimento desta pesquisa passa por uma ampla revisão bibliográfica em livros, dissertações, teses de doutorado, artigos, publicações e normas técnicas, com intuito de classificar e determinar as características e propriedades dos materiais envolvidos e métodos de dimensionamento.

O sistema desenvolvido neste trabalho, denominado MetalPro, utiliza três linguagens de programação, JavaScript (para a execução de ações e dimensionamento), HTML (estruturação do aplicativo) e CSS (estilo e aparência da plataforma) e foi construído com o auxílio da ferramenta Notepad++, que se trata de um ambiente de programação gratuito disponibilizado como um software livre.

Para facilitar a metodologia de dimensionamento dos pilares mistos e criação do algoritmo, desenvolveu-se um fluxo, baseado nas recomendações de Fakury, Castro e Silva e Caldas (2016), descrevendo as etapas a serem percorridas na determinação da capacidade resistente da peça em análise.

A estruturação do código divide-se em cinco etapas básicas:

(a)Introdução das características da seção em análise (Figura 2);

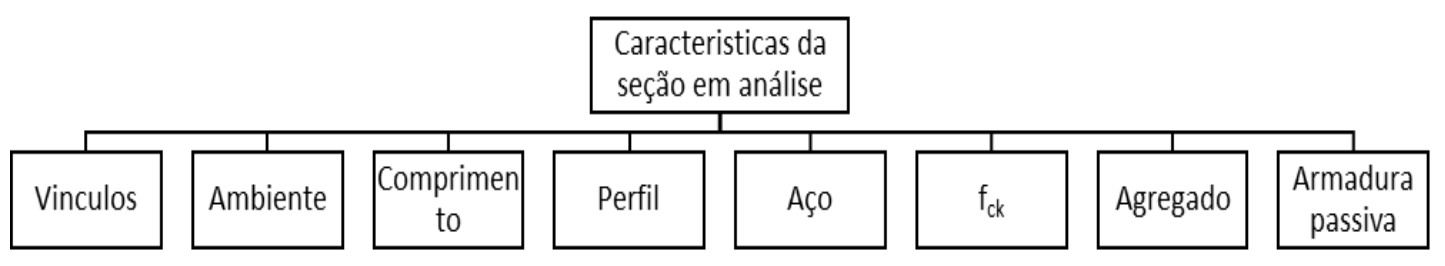

Figura 2 - Características da seção Fonte: Dos autores.

(b) Determinação das propriedades geométricas e mecânicas (Figura 3); 


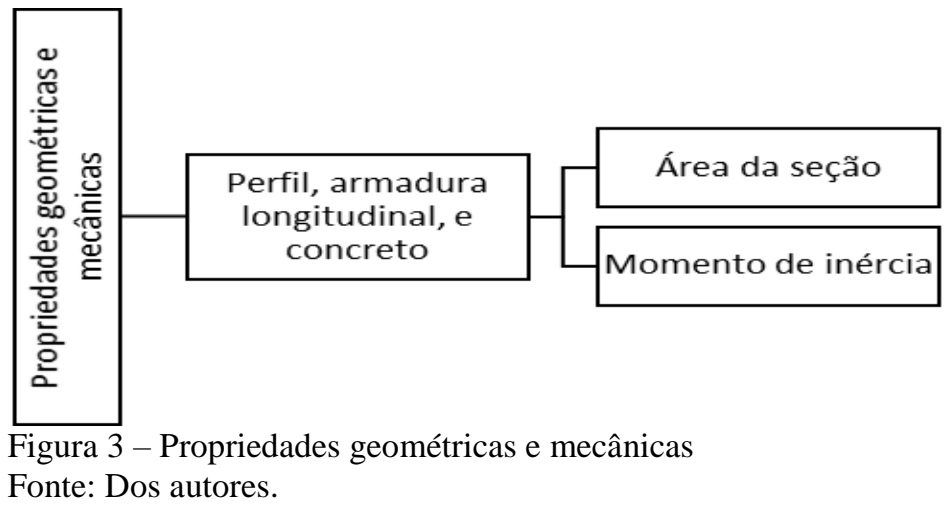

(c) Verificação dos critérios que evitem a ocorrência de flambagem local;

(d) Requisitos de projetos e limites de aplicabilidade (Figura 4);

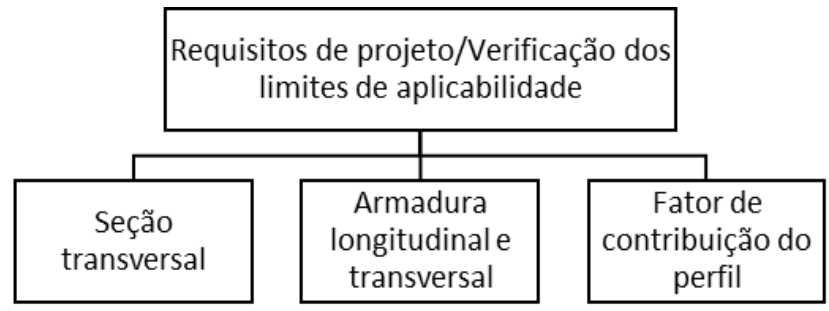

Figura 4 - Requisitos de projeto e limites de aplicabilidade Fonte: Dos autores.

(e) Determinação da força axial de compressão resistente de cálculo.

Com o intuito de verificar a lógica do aplicativo, a exatidão e precisão do código, são confeccionados exemplos práticos com o auxílio de uma planilha eletrônica, artifício utilizado por Serafim (2013).

Os exemplos analíticos contemplam pilares mistos parcialmente e totalmente preenchidos e englobam as diversas possibilidades previstas pela norma NBR 8800 (ABNT, 2008).

Submeteu-se, então, o código a um processo de validação cujos resultados foram comparados com resultados de dimensionamento de aplicações práticas.

\section{RESULTADOS E DISCUSSÃO}

\subsection{Sistema de dimensionamento de pilares mistos}

A ferramenta desenvolvida nesta pesquisa tem como base um banco de dados com informações, previamente cadastradas ou inseridas pelo usuário, sobre os materiais utilizados 
na composição de um pilar misto. Dados como o tipo de concreto, os tipos de aço e os perfis (laminados ou soldados) utilizados no dimensionamento, fazem parte desse cadastro geral.

$\mathrm{Na}$ Figura 5, apresenta-se a interface inicial do programa e o local de acesso ao cadastro de materiais.

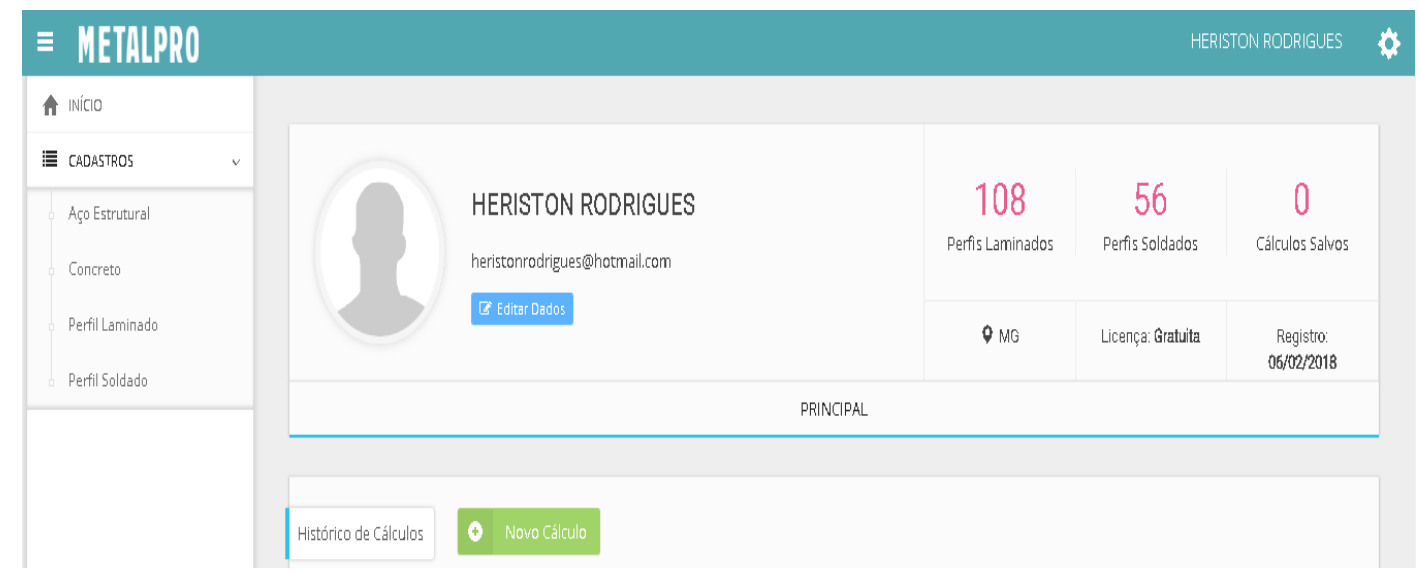

Figura 5 - Interface inicial do sistema

Fonte: Dos autores.

É permitida ao usuário a inclusão de novos materiais, desde que todas as informações que compõem o cadastro do material proposto sejam preenchidas na totalidade.

Para efetuar o cadastro, deve-se acessar o menu do material desejado (aço estrutural, concreto, perfil laminado ou perfil soldado) e selecionar a opção "adicionar" como exemplificado na Figura 6, liberando, dessa forma, a guia (Figura 7) em que são inseridas as propriedades referentes ao respectivo material.

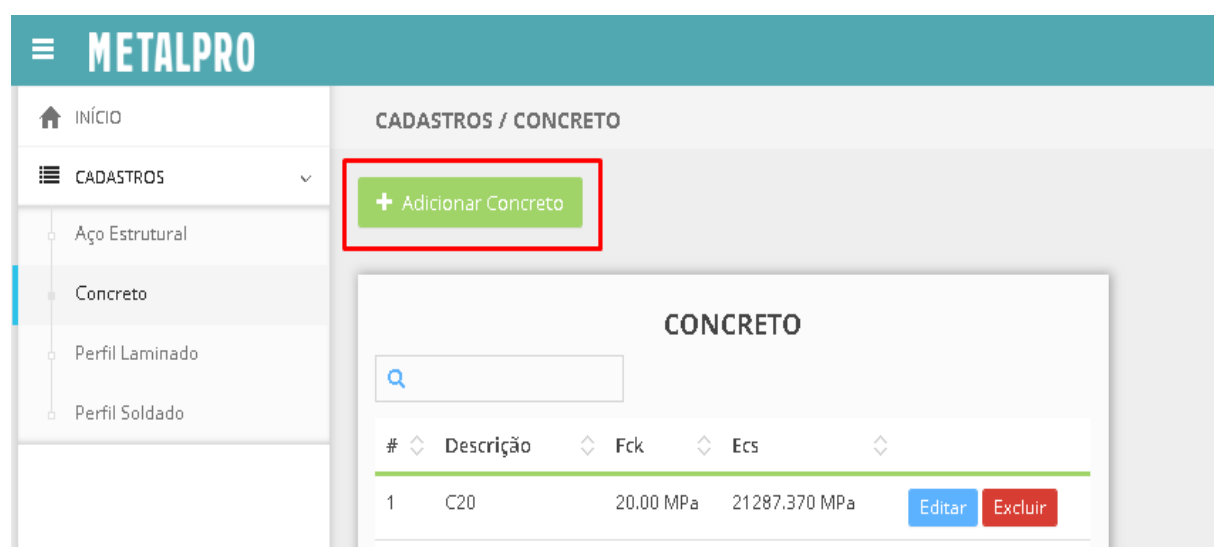

Figura 6 - Área de cadastro de materiais Fonte: Dos autores. 


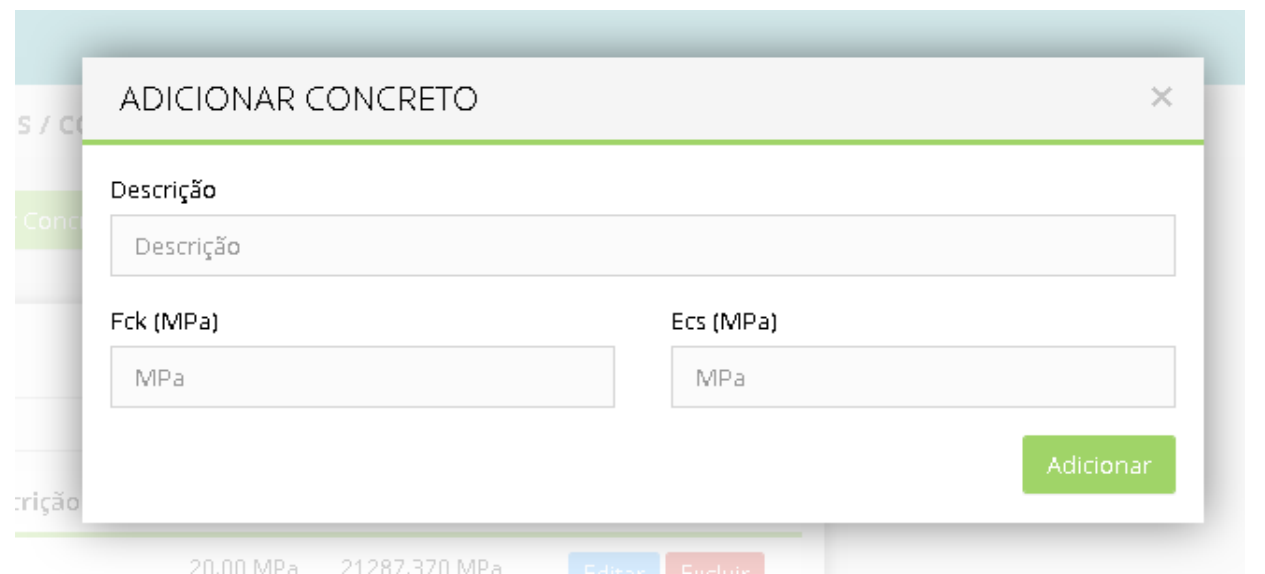

Figura 7 - Guia de inserção das propriedades de materiais Fonte: Dos autores.

O dimensionamento dos pilares mistos é precedido da inserção de informações de vinculação da peça, ambiente, materiais que compõem o pilar e os dados da seção. Tais informações devem ser inseridas no sistema pelo usuário e é essencial para o correto funcionamento da aplicação e, consequentemente, a certeza de precisão dos resultados.

Ao informar a vinculação, o usuário deve escolher, para as direções x e y, entre as situações previstas na tabela E.1 da norma NBR 8800 (ABNT, 2008), o que fornece ao sistema os valores dos coeficientes de flambagem $\mathrm{k}_{\mathrm{x}}$ e $\mathrm{k}_{\mathrm{y}}$. Para realizar a escolha, basta selecionar a opção, conforme demonstrado na Figura 8.

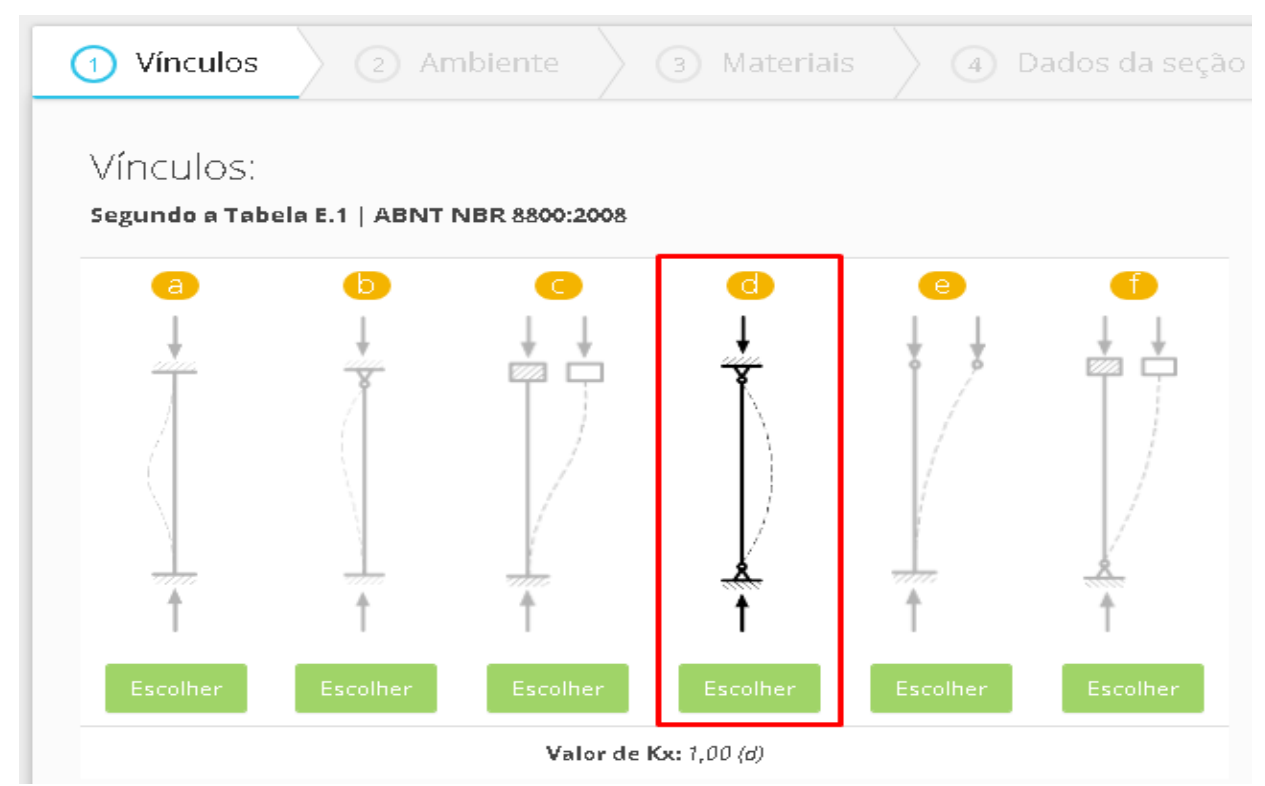

Figura 8 - Menu de escolha da vinculação Fonte: Dos autores. 
Na sequência da inserção dos dados para dimensionamento, o usuário deve selecionar o tipo de ambiente no qual o pilar em análise está inserido, indicando, assim, o cobrimento mínimo necessário para as armaduras que compõem o pilar misto. A escolha deve ser realizada como indicado na Figura 9.

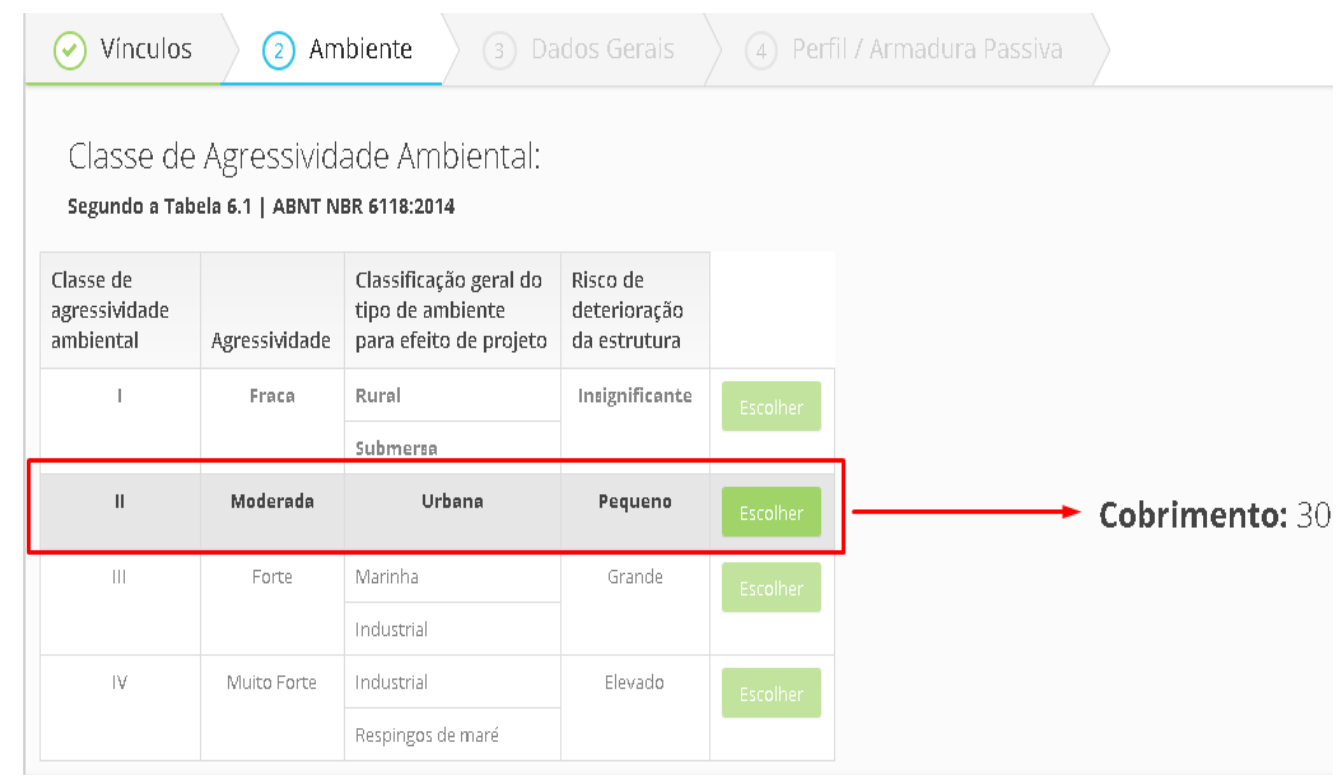

Figura 9 - Menu de escolha do ambiente

Fonte: Dos autores.

A definição dos materiais utilizados para compor o pilar misto é realizada nessa etapa seguindo a indicação presente na Figura 10 e as seguintes informações:

(a) Definição do comprimento do pilar, sendo esta a distância entre o apoio inferior e superior do pilar;

(b) Escolha do tipo de concreto a ser utilizado, cuja resistência característica a compressão apresente-se entre C20 e C50, permitindo ainda o cadastro de outros valores pelo usuário;

(c) Indicação do aço que compõe o perfil metálico, sendo aqueles que tenham qualificação estrutural assegurada por norma brasileira ou internacional;

(d) Seleção do aço da armadura longitudinal, com patamar de escoamento bem definido e aceitação de solda;

(e) Escolha do diâmetro máximo do agregado graúdo presente no concreto. Caso o usuário deseje, existe a possibilidade de desprezar o diâmetro máximo do 
agregado, permitindo, dessa forma, que as barras da armadura longitudinal tangenciando o perfil metálico.

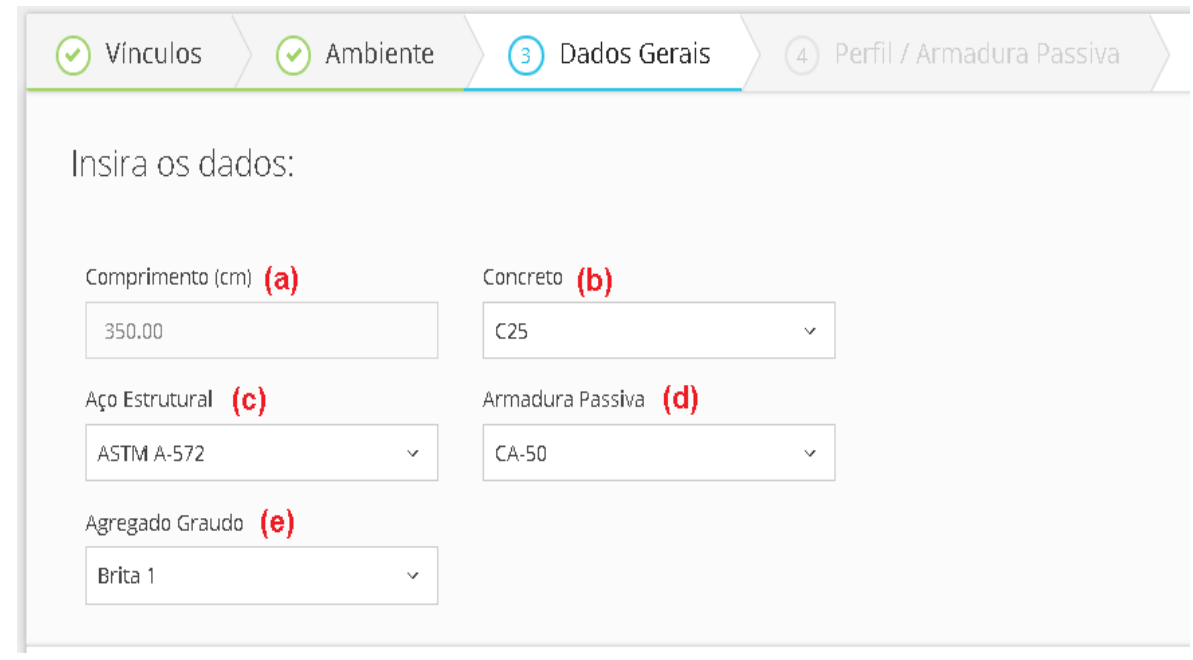

Figura 10 - Menu de escolha dos materiais Fonte: Dos autores.

A última etapa, precedente ao dimensionamento, consiste na inserção de dados referentes à seção transversal do pilar misto (Figura 11), sendo necessária a definição dos seguintes itens:

(a) Modelo do pilar, sendo possível a escolha entre parcialmente e totalmente preenchido;

(b) Tipo do perfil, tendo como opções peças laminadas ou soldadas;

(c) Diâmetro da armadura transversal (estribos);

(d) Diâmetro da armadura longitudinal, variando entre 10 e 20 mm;

(e) Armaduras adicionais nas direções $\mathrm{x}$ e $\mathrm{y}$. Nesse ponto, a aplicação insere automaticamente 4 barras, do diâmetro escolhido, próximo aos vértices da seção transversal, ficando a cargo do usuário somente a escolha de acrescentar ou não novas barras;

(f) Perfil utilizado;

(g) No caso de pilares totalmente preenchidos, os valores de $\mathrm{Cx}$ e $\mathrm{Cy}$. 


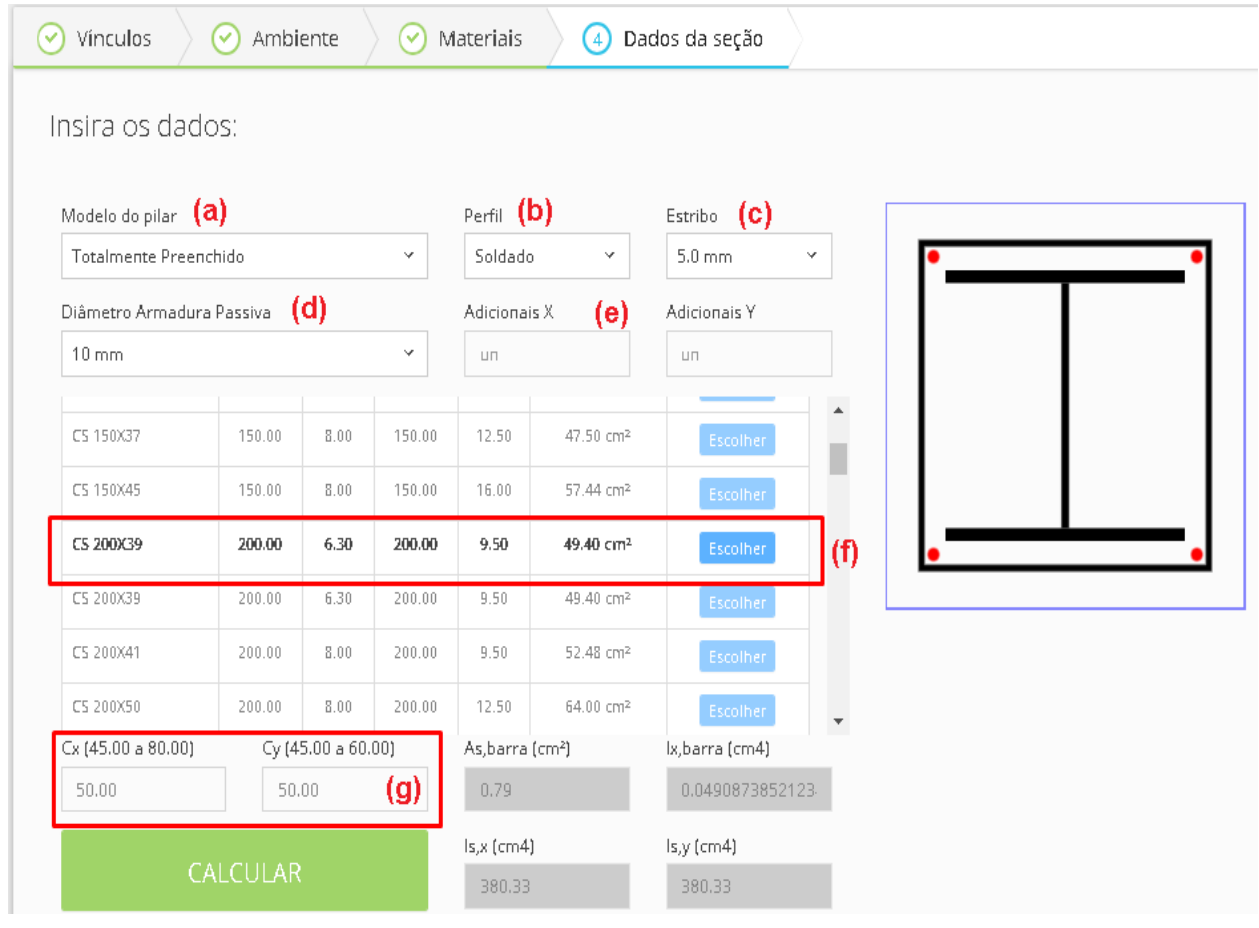

Figura 11 - Menu de inserção de dados da seção transversal Fonte: Dos autores.

Definidos os dados geométricos, o sistema gera automaticamente um detalhe esquemático da seção transversal, possibilitando ao usuário visualizar a configuração final do pilar misto em dimensionamento.

O programa tem como objetivo determinar a força axial de compressão resistente de cálculo. Para isso seu processo de cálculo é divido em quatro etapas:

(a) Determinação das propriedades geométricas e mecânica da seção;

(b) Verificação para não ocorrência de flambagem local da seção;

(c) Verificação dos limites de aplicabilidade;

(d) Determinação da força axial de compressão resistente de cálculo.

Na determinação das propriedades geométricas e mecânicas da seção, são calculadas, para o perfil metálico, as armaduras longitudinais e, para a seção de concreto, os valores de área, inercia nas direções x e y e tensões de projeto. No caso de perfis laminados, são adotadas as informações presentes no catálogo do fabricante e que se encontram previamente cadastradas. 
A verificação para não ocorrência de flambagem local da seção é realizada conforme a norma NBR 8800 (ABNT, 2008) sendo distintas para pilares totalmente preenchidos e pilares parcialmente preenchidos.

Nos pilares totalmente preenchidos, adotam-se os valores de cobrimento do perfil metálico dentro dos limites apresentados nas Equações 1 e 2:

$$
\begin{aligned}
& \mathrm{C}_{\mathrm{x}, \min } \leq \mathrm{C}_{\mathrm{x}} \leq \mathrm{C}_{\mathrm{x}, \max x} \\
& \mathrm{C}_{\mathrm{y}, \min } \leq \mathrm{C}_{\mathrm{y}} \leq \mathrm{C}_{\mathrm{y}, \max }
\end{aligned}
$$

Sendo:

$\mathrm{C}_{\mathrm{x}, \text { mín }}$ e $\mathrm{C}_{\mathrm{y} \text {,mín }}$ o menor entre os seguintes valores:

i. $40 \mathrm{~mm}$;

ii. $b_{\mathrm{f}} / 6$;

iii. $\mathrm{C}+\phi_{\text {Estribo }}+\phi_{\text {barra longitudinal }}+\mathrm{E}_{\text {agregado }}$

onde

$\mathrm{C}=$ cobrimento da armadura em função da agressividade ambiental;

$E_{\text {agregado }}=$ espaçamento mínimo entre armaduras longitudinais definidos na norma NBR 6118 (ABNT, 2014) e expressos pelas Equações 3 e 4.

$$
\begin{aligned}
& \mathrm{C}_{\mathrm{x}, \max }=0,40 \mathrm{~b}_{\mathrm{f}} \\
& \mathrm{C}_{\mathrm{y}, \max }=0,30 \mathrm{~d}
\end{aligned}
$$

Nos pilares parcialmente revestidos, deve ser atendido o seguinte a relação apresentada na Equação 5:

$$
b_{\mathrm{f}} / \mathrm{t}_{\mathrm{f}} \leq 1,49 \sqrt{\mathrm{E} / \mathrm{f}_{\mathrm{y}}}
$$

Na etapa de verificação dos limites de aplicabilidade, é avaliada a relação entre altura e largura da seção mista, a taxa de armadura longitudinal e o fator de contribuição do perfil metálico no conjunto. Todas as verificações respeitam os limites estabelecidos na NBR 8800 (ABNT, 2008). 
Por fim é realizada a determinação da força axial de compressão resistente de cálculo e todos os resultados são apresentados ao usuário na interface da aplicação em forma de relatório que pode, inclusive, ser exportado para arquivos formato PDF, além de ficarem salvos no sistema.

O sistema apresenta ao usuário, sempre que ocorrer alguma inconformidade, uma mensagem de erro na verificação não atendida, auxiliando, dessa forma, a correção da inconsistência.

\subsection{Validação do sistema}

A validação do sistema computacional está dividida em duas etapas, sendo a primeira a verificação dos resultados do sistema em relação aos pilares totalmente revestidos e a segunda a averiguação dos dados referentes aos pilares parcialmente revestidos.

Desenvolveram-se cinco aplicações práticas para cada tipo de pilar (totalmente e parcialmente revestidos), variando os valores dos seguintes dados de entrada:

i. Seção do perfil metálico;

ii. Aço do perfil metálico

iii. Resistência característica do concreto, $\mathrm{f}_{\mathrm{ck}}$;

iv. Coeficiente de flambagem nas direções x e y $\left(\mathrm{k}_{\mathrm{x}}\right.$ e $\left.\mathrm{k}_{\mathrm{y}}\right)$;

v. Comprimento do elemento;

vi. Quantidade de armadura passiva;

vii. Agregado do concreto;

viii. Agressividade do ambiente;

ix. Cobrimento do perfil metálico nas direções $\mathrm{x}$ e $\mathrm{y}$, quando pilar totalmente revestido.

A variação de características da peça analisada é fundamental para a total abrangência das situações previstas pela norma NBR 8800 (ABNT, 2008), garantindo confiabilidade, tanto do processo de validação como do funcionamento adequado do sistema.

Os exemplos de aplicação avaliados, neste trabalho, possuem características conforme demonstrado nas Figura 12-a, 12-b, Tabela 1 e

Tabela 2. 


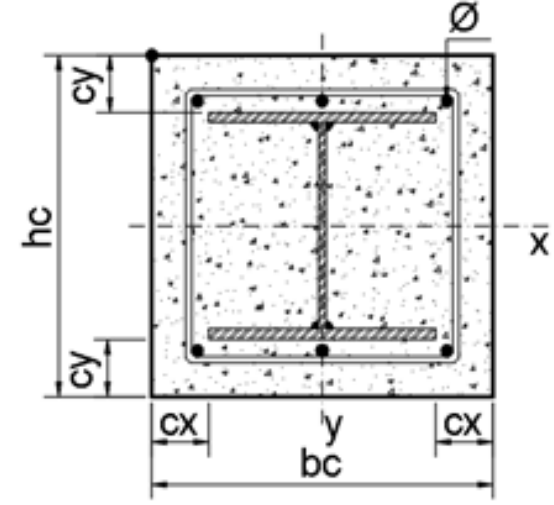

(a)



(b)

Figura 12 - Características das seções (a) totalmente revestidas e (b) parcialmente revestidas Fonte: Dos autores.

Tabela 1 - Dados dos utilizados na verificação dos pilares mistos totalmente revesitidos

\begin{tabular}{|c|c|c|c|c|c|}
\hline \multicolumn{6}{|c|}{ Dados dos Pilares Mistos Totalmente Revestidos } \\
\hline Características & Pilar 1 & Pilar 2 & Pilar 3 & Pilar 4 & Pilar 5 \\
\hline $\mathrm{b}_{\mathrm{c}}(\mathrm{mm})$ & 450 & 480 & 450 & 250 & 450 \\
\hline $\mathrm{h}_{\mathrm{c}}(\mathrm{mm})$ & 450 & 480 & 550 & 300 & 550 \\
\hline Seção do perfil metálico & CS 200x39 & $\begin{array}{c}\text { CS } \\
300 \times 102\end{array}$ & $\begin{array}{l}\text { W 360x91 } \\
(\mathrm{H})\end{array}$ & $\begin{array}{c}\mathrm{W} \\
200 \times 35,9 \\
(\mathrm{H})\end{array}$ & $\begin{array}{c}\text { CVS } \\
350 \times 73\end{array}$ \\
\hline Aço do perfil metálico & $\begin{array}{c}\text { USI } \\
\text { CIVIL } 350\end{array}$ & $\begin{array}{l}\text { ASTM } \\
\text { A-36 }\end{array}$ & $\begin{array}{l}\text { ASTM A- } \\
572\end{array}$ & $\begin{array}{l}\text { ASTM A- } \\
572\end{array}$ & $\begin{array}{l}\text { USI CIVIL } \\
350\end{array}$ \\
\hline $\mathrm{f}_{\mathrm{ck}}(\mathrm{MPa})$ & 25,0 & 35,0 & 40,0 & 20,0 & 30,0 \\
\hline $\mathrm{k}_{\mathrm{X}}$ & 1,0 & 2,10 & 0,80 & 2,10 & 0,80 \\
\hline $\mathrm{k}_{\mathrm{y}}$ & 1,0 & 0,65 & 1,20 & 2,00 & 1,00 \\
\hline $\begin{array}{l}\text { Comprimento do } \\
\text { elemento - L (m) }\end{array}$ & 3,00 & 5,50 & 3,15 & 3,70 & 2,80 \\
\hline $\begin{array}{l}\text { Armadura passiva } \\
\text { longitudinal } \mathrm{x}\end{array}$ & $6 \phi 10.0$ & $10 \phi 20.0$ & $8 \phi 12.5$ & $4 \phi 12.5$ & $16 \phi 20.0$ \\
\hline $\begin{array}{l}\text { Armadura passiva } \\
\text { longitudinal y }\end{array}$ & 0 & $6 \phi 20.0$ & $8 \phi 12.5$ & $2 \phi 12.5$ & $10 \phi 20.0$ \\
\hline$\phi$ armadura transversal & $\phi 5.0$ & $\phi 5.0$ & $\phi 5.0$ & $\phi 5.0$ & $\phi 5.0$ \\
\hline $\begin{array}{l}\text { Agregado do concreto } \\
(\mathrm{mm})\end{array}$ & $0,00 *$ & 19,0 & 12,50 & $0,00 *$ & 25,0 \\
\hline $\begin{array}{l}\text { Agressividade do } \\
\text { ambiente }\end{array}$ & II & III & IV & I & II \\
\hline $\mathrm{C}_{\mathrm{X}}(\mathrm{mm})$ & 50,0 & 90,0 & 98,0 & 42,5 & 100,0 \\
\hline $\mathrm{C}_{\mathrm{y}}(\mathrm{mm})$ & 50,0 & 90,0 & 98,5 & 49,5 & 100,0 \\
\hline
\end{tabular}

Fonte: Dos autores. 
Tabela 2 - Dados dos pilares mistos parcialmente revestidos utilizados na validação do sistema

\begin{tabular}{|c|c|c|c|c|c|}
\hline \multicolumn{6}{|c|}{ Dados dos Pilares Mistos Parcialmente Revestidos } \\
\hline Características & Pilar 1 & Pilar 2 & Pilar 3 & Pilar 4 & Pilar 5 \\
\hline $\mathrm{b}_{\mathrm{c}}(\mathrm{mm})$ & 152 & 300 & 154 & 250 & \\
\hline $\mathrm{h}_{\mathrm{c}}(\mathrm{mm})$ & 152 & 300 & 459 & 350 & \\
\hline Seção do perfil metálico & $\begin{array}{c}\mathrm{W} \\
150 \times 22,5\end{array}$ & $\begin{array}{c}\text { CS } \\
300 \times 76\end{array}$ & W 460x68 & $\begin{array}{c}\text { CVS } \\
350 \times 73\end{array}$ & $\begin{array}{c}\text { CS } \\
700 \times 458\end{array}$ \\
\hline Aço do perfil metálico & $\begin{array}{l}\text { ASTM A- } \\
572\end{array}$ & $\begin{array}{c}\text { ASTM } \\
\text { A-36 }\end{array}$ & $\begin{array}{l}\text { ASTM A- } \\
572\end{array}$ & $\begin{array}{c}\text { USI } \\
\text { CIVIL } \\
300\end{array}$ & $\begin{array}{c}\text { ASTM A- } \\
36\end{array}$ \\
\hline $\mathrm{f}_{\mathrm{ck}}(\mathrm{MPa})$ & 30,0 & 35,0 & 25,0 & 40,0 & 45,0 \\
\hline $\mathrm{k}_{\mathrm{x}}$ & 1,00 & 2,10 & 0,80 & 2,10 & 1,00 \\
\hline $\mathrm{k}_{\mathrm{y}}$ & 1,00 & 0,65 & 1,20 & 0,80 & 1,00 \\
\hline $\begin{array}{l}\text { Comprimento do } \\
\text { elemento - L (m) }\end{array}$ & 2,80 & 5,50 & 3,80 & 3,20 & 3,15 \\
\hline $\begin{array}{c}\text { Armadura passiva } \\
\text { longitudinal } \mathrm{x}\end{array}$ & $4 \phi 12.5$ & $8 \phi 10.0$ & $4 \phi 10.0$ & $8 \phi 12.5$ & $12 \phi 16.0$ \\
\hline $\begin{array}{c}\text { Armadura passiva } \\
\text { longitudinal y }\end{array}$ & 0 & $4 \phi 10.0$ & $2 \phi 10.0$ & 0 & $4 \phi 16.0$ \\
\hline$\phi$ armadura transversal & $\phi 5.0$ & $\phi 5.0$ & $\phi 5.0$ & $\phi 5.0$ & $\phi 5.0$ \\
\hline $\begin{array}{l}\text { Agregado do concreto } \\
(\mathrm{mm})\end{array}$ & 19,0 & 19,0 & $0,00 *$ & 25,0 & 25,0 \\
\hline $\begin{array}{l}\text { Agressividade do } \\
\text { ambiente }\end{array}$ & II & III & III & I & II \\
\hline
\end{tabular}

Utilizando de informações obtidas através de uma modelagem analítica das aplicações práticas, desenvolveu-se uma planilha eletrônica para auxiliar no processo de geração de resultados para a averiguação do aplicativo.

A aferição da planilha eletrônica dá-se através de um comparativo entre seus resultados e os valores de uma aplicação prática desenvolvida analiticamente Fakury, Castro e Silva e Caldas (2016). Através dessa comparação, é possível, ainda, estabelecer uma margem aceitável de variação entre os resultados do sistema e a planilha.

Cada exemplo de aplicação é dimensionado com auxílio da planilha eletrônica e no programa desenvolvido, obtendo-se, dessa forma, os resultados para cada etapa de dimensionamento e o valor de resistência final das peças analisadas.

Na Figura 13, apresenta-se um comparativo entre os valores finais de carga axial de compressão resistente de cálculo determinadas pelo sistema e de forma analítica. 


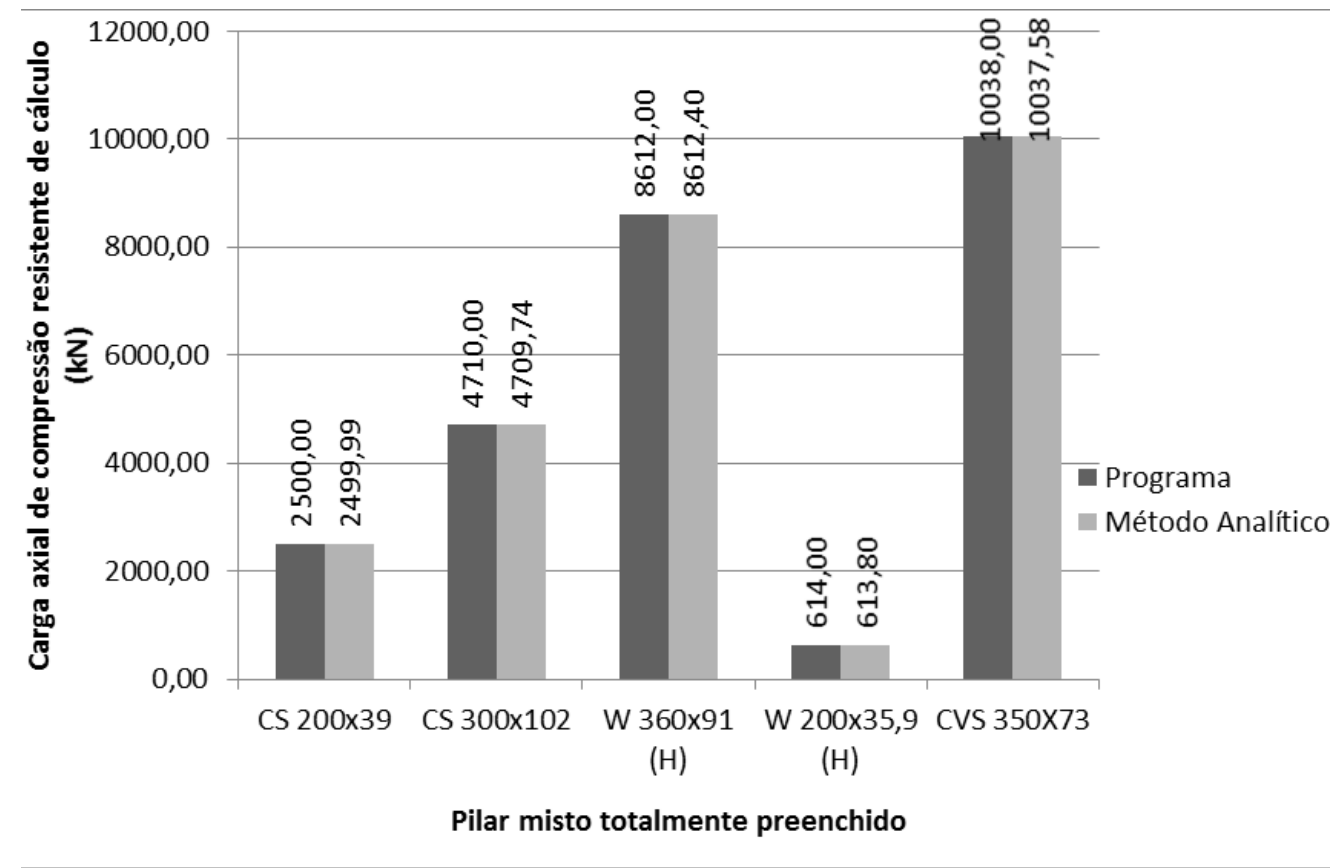

Figura 13 - Valores de carga axial de compressão resistente de cálculo para pilares totalmente revestido Fonte: Dos autores.

O comparativo entre as cargas axiais resistentes de cálculo, determinadas pelo método automatizado e analítico, para seções mistas parcialmente preenchidas é apresentado na Figura 14.

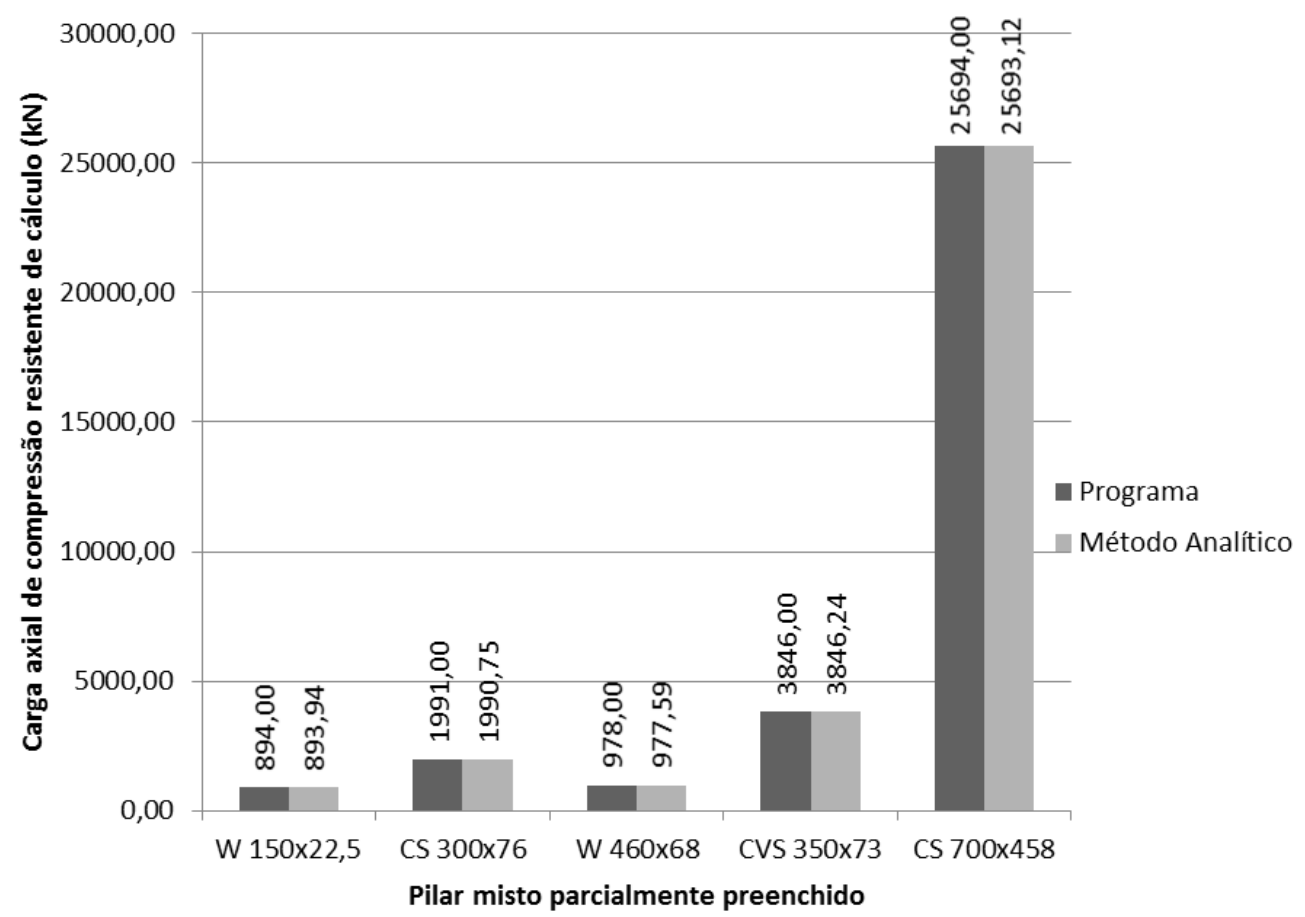

Figura 14 - Comparativo entre os valores de carga axial de compressão resistente de cálculo, de pilares parcialmente revestido.

Fonte: Dos autores. 
Para as seções totalmente preenchidas, a maior diferença encontrada foi igual a $0,03 \%$ para a seção mista composta pelo perfil W200x35,9 (H).

Avaliando as seções parcialmente preenchidas, a maior diferença observada foi de 0,04\% na determinação da força axial de compressão resistente de cálculo no pilar misto composto pelo perfil $\mathrm{W} 460 \times 68$.

Dentro da metodologia proposta, são realizadas comparações em cada etapa do dimensionamento, verificando a convergência entre as informações geradas pelo programa e de maneira analítica. Essa comparação permite identificar qualquer diferença entre os resultados do aplicativo e os exemplos de aplicação. As máximas variações encontradas estão apresentadas na Tabela 3 .

Tabela 3 - Comparação geral dos resultados gerados analiticamente e pelo programa

\begin{tabular}{cc}
\hline Etapa de dimensionamento & Máxima variação encontrada (\%) \\
\hline $\begin{array}{c}\text { Determinação das propriedades } \\
\text { geométricas e mecânica da seção }\end{array}$ & 0,00 \\
\hline $\begin{array}{c}\text { Verificação para não ocorrência de } \\
\text { flambagem local da seção }\end{array}$ & 0,00 \\
\hline Verificação dos limites de aplicabilidade & 0,00 \\
\hline $\begin{array}{c}\text { Determinação da força axial de } \\
\text { compressão resistente de cálculo }\end{array}$ & 0,04 \\
\hline
\end{tabular}

Fonte: Dos autores.

Dada a comparação geral dos resultados, nota-se uma variação máxima de $0,04 \%$, entre a metodologia de dimensionamento analítico e o cálculo realizado pelo sistema, na determinação da força axial de compressão resistente de cálculo.

\subsection{Discussão dos resultados}

O sistema desenvolvido possui uma boa interação com o usuário, apresentando telas e funcionalidades amigáveis e de fácil entendimento. A linguagem utilizada facilita a interatividade, pois permite adicionar efeitos e mensagens tornando a aplicação extremamente dinâmica.

Por estar instalado na rede global de computadores, o utilitário permite acesso em locais com internet, tornando qualquer trabalho viável e garantindo a integridade dos dados salvos sem necessidades de cópias de segurança. Outra funcionalidade do programa é a 
compatibilidade com a maioria dos navegadores modernos e sistemas operacionais, adequando-se, dessa forma, ao estilo de navegação e utilização dos usuários tornando-o acessível a diversos interessados.

Ao realizar o dimensionamento, o aplicativo possui como premissas as restrições estabelecidas pela norma NBR 8800 (ABNT, 2008), quanto ao modelo de cálculo simplificado adotado para o dimensionamento de pilares mistos de aço e concreto.

Os resultados demonstram uma avaliação ampla do aplicativo, em que foram realizados 10 testes, conseguindo-se, dessa forma, aferir diversos limites e critérios impostos pela norma NBR 8800 (ABNT, 2008), evidenciando que o sistema foi elaborado de forma adequada. Observa-se também uma equidade dos resultados, como era previsto devido à utilização do mesmo equacionamento teórico, comprovando uma implementação do algoritmo de maneira assertiva, tornando o aplicativo viável e seguro para utilização.

As pequenas diferenças encontradas podem ser explicadas por uma variação de aproximação matemática entre as duas formas de cálculo, o programa e analiticamente. Ressalta-se ainda que tal variação é tolerável e que não afeta a segurança estrutural, por se tratar de uma variação pouco significativa decorrente da aproximação no cálculo.

É importante ressaltar que os resultados finais apresentados pelo programa são oriundos das informações inseridas pelo usuário, sendo crucial o cadastramento de dados confiáveis e verificados, obtendo-se, assim, resultados precisos e que poderão ser, após verificação final do interessado, operados com segurança. Deve-se frisar que o aplicativo atua exclusivamente no dimensionamento de pilares mistos aço e concreto, compostos por perfis de seção transversal $\mathrm{I}$ ou $\mathrm{H}$, totalmente ou parcialmente preenchidos.

\section{CONCLUSÃO}

Neste estudo foi desenvolvido um programa computacional para dimensionamento de pilares mistos de aço-concreto submetidos à compressão centrada. A aplicação foi capaz de sistematizar todas as verificações necessárias ao cálculo de pilares mistos nessa condição.

O sistema mostrou-se eficiente e preciso após a validação dos resultados, em que foram comparados com valores obtidos automática e analiticamente. Na validação, não foram encontradas diferenças consideráveis, e provavelmente provenientes de aproximação matemática, demonstrando a qualidade do instrumento computacional e evidenciando o atendimento dos critérios de segurança. 
O aplicativo atende todas as considerações da norma NBR 8800 (ABNT, 2008), e pode ser utilizado como ferramenta auxiliar na execução de projetos em estruturas mistas. Desde que seja aplicado adequadamente, com conhecimento tecnológico e respeito às boas práticas de projeto, o sistema apresenta um grande ganho de eficiência.

O programa facilita a execução de diversas alternativas de pilares mistos, em um curto período de tempo, possibilitando ao usuário a melhor escolha e tornando a concepção estrutural econômica e eficaz, além disso, auxilia na disseminação da construção metálica no Brasil, pois permite a popularização da metodologia de projetos de estruturas mistas de aço e concreto, por ser uma ferramenta gratuita, de qualidade e de alta precisão.

O sistema demonstra, de forma detalhada, os resultados obtidos e emite relatórios de dimensionamento, o que possibilita sua utilização com finalidade didática, permitindo ao docente demonstrar diversas situações de projeto, conceituando todos os itens normativos, durante as aulas.

Por estar disponibilizado na rede mundial de computadores, o sistema possibilita uma maior flexibilidade aos usuários que poderão acessar todos os dados salvos de qualquer lugar com acesso a internet, além de conferir maior segurança sem a necessidade de realização de cópias de segurança.

\title{
AGRADECIMENTOS
}

Os autores agradecem ao programa de Pós-Graduação em Construção Metálica e ao apoio concedido pela CAPES (Coordenação de Aperfeiçoamento de Pessoal de Nível Superior).

\section{COMPUTER PROGRAM FOR THE DIMENSIONING OF STEEL AND CONCRETE COMPOSITE COLUMNS SUBJECTED TO CENTERED COMPRESSION}

\begin{abstract}
The advancement of metal constructions in Brazil demands skilled professionals and endowed with effective tools in the elaboration of projects. A program was developed capable of dimensioning composite columns of steel and concrete submitted to centered compression, meeting Brazilian normative requirements. The tool was built in the programming environment Notepad $++\mathrm{v} 7.5 .6$ following the procedures proposed by the brazilian standard NBR 8800 (ABNT, 2008). A process of validation of its results was also carried out comparing them to application examples developed analytically with the aid of spreadsheets.
\end{abstract}


The program provides precise results, can assist professionals in the development of projects, is capable of being a complementary tool in the teaching process and in the dissemination of the composite metallic structural system.

Keywords: Composite structure. Composite pillar. Sizing program.

\section{REFERÊNCIAS}

ALVA, Gerson Moacyr Sisniegas; MALITE, Maximiliano. Comportamento estrutural e dimensionamento de elementos mistos aço-concreto. Cadernos de Engenharia de Estruturas São Carlos, São Carlos, v. 7, n. 25, p. 51-84, 2005.

ASSOCIAÇÃO BRASILEIRA DE NORMAS TÉCNICAS - ABNT. NBR 6118: Projeto de estruturas de concreto: procedimento. Rio de Janeiro, 2014.

ASSOCIAÇÃO BRASILEIRA DE NORMAS TÉCNICAS - ABNT. NBR 8800: Projetos de estruturas de aço e de estruturas mistas de aço e concreto de edifícios: procedimento. Rio de Janeiro, 2008.

CAMPOS, Alessandro de Souza. Estudo sobre os critérios de dimensionamento de pilares mistos de aço e concreto. 2006. 156 f. Dissertação (Mestrado em Engenharia Civil) Faculdade de Engenharia Civil, Arquitetura e Urbanismo, Universidade Estadual de Campinas, Campinas, 2006.

CARDOSO, Nuno Filipe Almeida. Dimensionamento e comparação de custos de execução de lajes a grande altura com soluções tradicionais escoradas e em estrutura mista aço e betão. 2013. 161 f. Dissertação (Mestrado Integrado em Engenharia Civil) - Faculdade de Engenharia, Universidade do Porto, Porto, Portugal, 2013.

CHAVES, Leonardo Eustáquio Antunes. Estudo de pilares de concreto armado e pilares mistos de aço e concreto totalmente revestidos. 2013. 98 f. Dissertação (Mestrado em Engenharia de Estruturas) - Escola de Engenharia, Universidade Federal de Minas Gerais, Belo Horizonte, 2013.

FABRIZZI, Marcela de Arruda. Contribuição para o projeto e dimensionamento de edifícios de múltiplos andares com elementos estruturais mistos aço - concreto. 2007. 233 f. Dissertação (Mestrado em Engenharia de Estruturas) - Escola de Engenharia de São Carlos, Universidade de São Paulo, São Carlos, 2007.

FAKURY, Ricardo Hallal; CASTRO E SILVA, Ana Lydia Reis de; CALDAS, Rodrigo Barreto. Dimensionamento básico de elementos estruturais de aço e mistos de aço e concreto. São Paulo: Pearson Education do Brasil, 2016.

FIGUEIREDO, Luciana Maria Bonvino. Projeto e construção de pilares mistos açoconcreto. 1998. 143 f. Dissertação (Mestrado em Engenharia de Estruturas) - Escola de Engenharia de São Carlos, Universidade de São Paulo, São Carlos, 1998.

MENDONÇA, Paulo Jorge Cunha; VIEIRA, Maria do Carmo; VENÂNCIO, José. A utilização de pilares mistos em edifícios: concepção, dimensionamento e execução - Edifício 
Ges - Luanda. CONGRESSO DE CONSTRUÇÃO METÁLICA E MISTA, 5., 2005, Lisboa. Actas... Lisboa, 2005. p. II-449 - II-458.

QUEIROZ, Gilson; PIMENTA, Roberval José; MARTINS, Alexander Galvão. Estruturas mistas. 2. ed. Rio de Janeiro: Instituto Aço Brasil/CBCA, 2012. v. 1.

RODRIGUES, Luís Filipe Pires. Desenvolvimento de um toolkit em Excel para o dimensionamento de pilares mistos segundo Eurocódigo 4. 2008. 116 f. Dissertação (Mestrado Integrado em Engenharia Civil) - Faculdade de Engenharia, Universidade do Porto, Porto, Portugal, 2008.

SERAFIM, Jorge Augusto. Pilares mistos de aço e concreto parcialmento revestidos: comportamento isolado, inserção em galpões industriais e comparativos com pilares de sistemas estruturais usuais. 2014. 118 f. Dissertação (Mestrado em Estruturas e Construção Civil) - Centro de Ciências Exatas e de Tecnologia, Universidade Federal de São Carlos, São Carlos, 2013.

SILVA, Paulo Henrique Lubas. Dimensionamento de pilares mistos de aço e concreto. 2012. 314 f. Dissertação (Mestrado em Engenharia) - Escola Politécnica, Universidade de São Paulo, São Paulo, 2012.

\section{DADOS DOS AUTORES}

\section{Heriston Rodrigues}

E-mail: heriston.rodrigues@ifmg.edu.br Currículo Lattes: http://lattes.cnpq.br/2145666202938631

Mestrando Profissional em Construção Metálica pela Universidade Federal de Ouro Preto (UFOP). Especialização em Planejamento e Controle de Obras (em andamento) pela Universidade Paulista (UNIP) e Especialização em Estruturas de Concreto e Fundações (2015) pela Universidade Cidade de São Paulo (UNICID). Possui graduação em Engenharia Civil e Ambiental pela Universidade Vale do Rio Doce. Atualmente é professor do ensino básico, técnico e tecnológico do Instituto Federal Minas Gerais - IFMG - Campus Valadares.

\section{Geraldo Donizetti de Paula}

E-mail: gdepaula9@gmail.com

Currículo Lattes: http://lattes.cnpq.br/6267945082164521

Doutorado em Engenharia Civil (Engenharia de Estruturas) pela Universidade de São Paulo (USP), mestrado em Engenharia Civil (Engenharia de Estruturas) pela USP e graduação em Engenharia Civil pela UFOP. Atualmente é professor associado da UFOP.

\section{Jaime Florêncio Martins}

E-mail: jaimeufop@gmail.com

Currículo Lattes: http://lattes.cnpq.br/1362320121241835

Doutorado em Estruturas pela Escola de Engenharia de São Carlos USP, mestrado em Estruturas pela EESC/USP e atualmente é professor Titular da UFOP. Foi tutor do Grupo PET Engenharia Civil da UFOP de 1992 a 1993 e de 2001 até Julho de 2013. 